\title{
ESPECTRO DAS GOTAS PRODUZIDAS POR PONTAS DE JATO PLANO DUPLO DEFASADO COM INDUÇ̃̃O DE AR
}

Robson Shigueaki Sasaki ${ }^{1}$, Mauri Martins Teixeira ${ }^{2}$, Christiam Felipe Silva Maciel ${ }^{3}$, Cleyton Batista de Alvarenga ${ }^{4}$, Paulo Roberto Forastiere ${ }^{5}$

\section{RESUMO}

Os fabricantes de pontas de pulverização constantemente disponibilizam novos modelos no mercado na tentativa de aumentar a eficiência das aplicações, entretanto muitas vezes seu comportamento é desconhecido em relação ao espectro das gotas produzidas. Sendo assim, este trabalho foi conduzido com o objetivo de avaliar o espectro de gotas proporcionado pelas pontas AI3070-015VP e AI3070-02VP. Estas apresentam dois jorros de pulverização defasados em relação à vertical $\left(30\right.$ e $\left.70^{\circ}\right)$, ambos com indução de ar. Na análise do espectro, utilizou-se um analisador de partículas a laser (Spraytec, Malvern Instruments Co.) dotado de lente focal de $750 \mathrm{~mm}$. Construiu-se um sistema para analisar individualmente os jorros produzidos pelas pontas. Realizaram-se as análises dos parâmetros técnicos da pulverização (DV0,1, DV0,5, DV0,9, Índice Span, $\% \mathrm{~V}<100 \mu \mathrm{m}$ e $\% \mathrm{~V}>650 \mu \mathrm{m}$ ) empregando-se quatro pressões de trabalho $(200,300,400$ e $500 \mathrm{kPa})$. O experimento foi conduzido em delineamento inteiramente ao acaso, em esquema fatorial $(2 \times 2 \times 4)$, sendo dois modelos de pontas hidráulicas dois leques e quatro pressões de trabalho. Para a ponta AI3070-015VP o jorro produzido com ângulo de $70^{\circ}$ produziu gotas com maior diâmetro da mediana volumétrica (DMV) em relação ao de $30^{\circ}$ ao passo que, para a ponta AI3070-02VP, o comportamento foi o inverso. As pontas testadas apresentaram gotas com baixo potencial de deriva, com $\% \mathrm{~V}<100 \mu \mathrm{m}$ de no máximo $10,8 \%$, quando avaliou a maior pressão de trabalho.

Palavras-Chave: AI3070, pulverização hidráulica, tecnologia de aplicação de produtos fitossanitários

\section{ABSTRACT \\ DROPLETS SPECTRUM PRODUCED BY AIR INDUCTION DUAL PATTERN FLAT SPRAY NOZZLES}

The spray nozzles manufacturers constantly offer new models in the market attempting to increase the application efficiency; however, the nozzles behavior is often unknown in relation to the produced droplets spectrum. Thus, this work was carried out aiming to evaluate the droplets spectrum provided by the AI3070-015VP and AI3070-02VP nozzles. These nozzle tips have two tilted sprays $\left(30\right.$ and $\left.70^{\circ}\right)$ both with air induction. In the spectrum analysis, it was used the laser particle analyzer (Spraytec, Malvern Instruments Co.) which has a $750 \mathrm{~mm}$ focal lens. It was built a system to analyze the spray jets produced by the nozzles individually. The spraying technical parameters $\left(\mathrm{DV}_{0,1}\right.$, $\mathrm{DV}_{0,5}, \mathrm{DV}_{0,9}$, Span Index, $\% \mathrm{~V}<100 \mu \mathrm{m}$ and $\left.\% \mathrm{~V}>650 \mu \mathrm{m}\right)$ were performed in four working pressures $(200,300,400$ and $500 \mathrm{kPa})$. The experiment was conducted in a completely randomized in a factorial scheme $(2 \times 2 \times 4)$, two models of nozzle sprayer, two fan and four working pressures. For the AI3070-015VP nozzle, the tilted $70^{\circ}$ spray produced droplets with coarser volume median diameter (VMD) comparing to the tilted $30^{\circ}$ spray, whereas for the AI3070$02 \mathrm{VP}$ nozzle, the behavior was the opposite. The nozzles tested showed low drift potential, with $\% \mathrm{~V}<100 \mu \mathrm{m}$ up to $10.8 \%$ when tested in the higher working pressure.

Keywords: AI3070, hydraulic spraying, pesticides spraying technology

Recebido para publicação em 06/07/2015. Aprovado em 16/06/2016.

1 - Engenheiro Agrônomo, Professor do IFMG/ Bambuí-MG, Departamento de Engenharia e Computação, robson.sasaki@ifmg.edu.br

2 - Engenheiro Agrônomo, Professor da UFV/Viçosa-MG, Departamento de Engenharia Agrícola, mauri@ufv.br

3 - Engenheiro Agrônomo, Doutorando, UFV/Viçosa-MG, christiammaciel@gmail.com

4 - Engenheiro Agrônomo, Professor, UFU/ Monte Carmelo-MG, Departamento de Engenharia Agrícola, cleyton@iciag.ufu.br

5 - Engenheiro Agrônomo, Doutorando, UFV/Viçosa-MG, Departamento de Engenharia Agrícola, paulo.forastiere@gmail.com 


\section{INTRODUÇÃO}

A aplicação de agrotóxicos é uma das principais atividades na produção agrícola e exige muita atenção na seleção das pontas de pulverização e posterior regulagem e calibração das máquinas para aplicação de defensivos agrícolas. As pontas de pulverização podem ser consideradas um dos componentes mais importantes dos equipamentos para aplicação de agrotóxicos, por determinar as características do jato emitido, regular a vazão e controlar o tamanho das gotas (CUNHA et al., 2007).

As pontas hidráulicas são componentes essenciais dos pulverizadores, o que estimula os fabricantes a desenvolverem e disponibilizarem com frequência novas alternativas aos produtores. Uma escolha bem feita pode garantir a eficiência da aplicação, bem como a eficácia do produto fitossanitário. Esta tarefa parece simples, entretanto existem muitas dúvidas em torno do tamanho ideal de gotas a ser empregado em uma pulverização. $\mathrm{Na}$ escolha das pontas a serem utilizadas, devese conhecer o espectro de gotas produzido. Sabese que gotas finas aumentam a cobertura do alvo, porém aquelas menores que $100 \mu \mathrm{m}$ são mais suscetíveis à deriva (ARVIDSSON et al., 2011). Por outro lado, gotas muito grossas são menos afetadas pelo efeito das condições psicrométricas do ar como evaporação e deriva, porém estão mais sujeitas às perdas por escorrimento. Neste sentido, deve-se ajustar o tamanho das gotas na pulverização de acordo com o alvo a ser atingido, condições meteorológicas no momento da pulverização, produto a ser aplicado e a técnica empregada.

A escolha da ponta é uma etapa fundamental para a eficácia dos tratamentos fitossanitários, Gulart et al. (2013) observaram maior deposição da calda na cultura do trigo, quando utilizaram pontas que produziram maior tamanho de gotas, por sua vez Lenz et al. (2012) constataram maior eficácia de controle e velocidade de absorção de fungicidas quando utilizaram gotas de menor tamanho.

$\mathrm{Na}$ seleção do melhor tamanho de gotas para realizar a aplicação de agrotóxicos, é necessário considerar os fatores meteorológicos. No Brasil, as aplicações têm sido realizadas em diferentes horários durante o dia e a noite. A perda por evaporação de gotas nas horas de maior temperatura e menor umidade relativa e potencial risco de deriva das gotas pulverizadas contribuiu para o desenvolvimento de pontas com tecnologia para aumentar o tamanho das gotas, destacando-se as pontas hidráulicas com indução de ar e jorro do tipo leque duplo. As pontas com indução aspiram o ar para o seu interior através de pequenos orifícios e este é misturado com o líquido a ser pulverizado (VALLET; TINET, 2013).

As pontas com indução de ar e jorro do tipo leque simples geralmente produzem gotas grossas. Bueno et al., (2013) avaliaram pontas do tipo indução de ar leque simples e observaram valores de DMV na ordem de até $543 \mu \mathrm{m}$, porém, o espectro de gotas das pontas com indução de ar do tipo leque duplo defasado ainda é pouco conhecido. A hipótese da pesquisa foi averiguar se os diferentes leques proporcionados por um determinado modelo de ponta possuem comportamento semelhante quanto ao diâmetro de gotas pulverizadas. Sendo assim, objetivou-se analisar o espectro de gotas de pontas do tipo leque duplo defasado com indução de ar em diferentes condições operacionais.

\section{MATERIAL E MÉTODOS}

O experimento foi realizado no Laboratório de Tecnologia de Aplicação de Defensivos Agrícolas (LADA), pertencente ao Departamento de Engenharia Agrícola da Universidade Federal de Viçosa, Viçosa, Minas Gerais.

Foram utilizadas pontas hidráulicas de jato plano duplo defasado, modelo AI3070-015VP e AI3070-02VP, fabricadas pela TeeJet ${ }^{\circledR}$. Ambas apresentam dois jatos planos com indução de ar defasados por um ângulo entre os jorros de $30 \mathrm{e}$ $70^{\circ}$ graus, em duas direções de pulverização em relação à vertical.

As pontas foram montadas em uma bancada padronizada de acordo com a norma ISO 5682-1, com a finalidade de avaliar a vazão proporcionada pela ponta em função da pressão de trabalho. $\mathrm{O}$ fabricante recomenda para ambas as pontas a faixa de pressão entre 140 a $633 \mathrm{kPa}$, sendo este estudo realizado nas pressões recomendadas de 200, 300,400 e $500 \mathrm{kPa}$. O manômetro utilizado no experimento foi da marca Farmabras, com precisão de $20 \mathrm{kPa}$, calibrado em bancada por comparação com o manômetro padrão Classe A3.

A fim de estudar o espectro de gotas, as pontas foram colocadas em uma barra de pulverização com movimento rotativo de $180^{\circ}$ de modo a garantir a análise de todo o jorro. Para realizar este movimento, em uma das extremidades da barra utilizou-se um motoredutor elétrico, marca Bosch, modelo $\mathrm{CEP}, 12 \mathrm{~V}$ e torque máximo de $48 \mathrm{~N} \mathrm{~m}$,

\section{REVENG}


acionado por uma chave elétrica (liga/desliga).

Em função do leque duplo defasado em 30 e $70^{\circ}$ construiu-se um bojo de chapa metálica, de 0,65 m de largura e 0,26 $\mathrm{m}$ de profundidade, coberto com grama artificial, com a finalidade de individualizar os leques da ponta de pulverização. Primeiramente, realizou-se a leitura do leque com angulação de $30^{\circ}$ e em seguida do leque de $70^{\circ}$. Para realizar a leitura do segundo leque, inverteu-se o bojo e instalou uma curva de PVC com $70^{\circ}$, para desviar o fluxo de água e impedir que o jato atingisse a lente do laser (Figura 1). As avaliações do espectro de gotas foram realizadas utilizando-se um analisador de partículas em tempo real (Spraytec, Malvern Instruments Co.), dotado de lente focal de 750 $\mathrm{mm}$ e configurado para contabilizar gotas de 0,10 a $2.500 \mu \mathrm{m}$, com taxa de aquisição de $2,5 \mathrm{kHz}$ e tempo de leitura de 1,5 s.

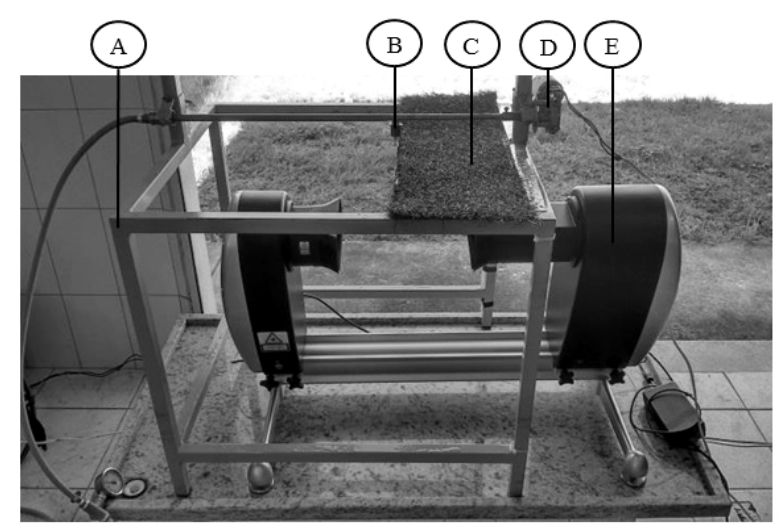

Figura 1. Sistema desenvolvido para realizar a leitura individualizada dos jorros de pulverização. A. Estrutura metálica; B. Ponta de pulverização hidráulica; C. Bojo para individualizar os leque e coletar a água; D. Motoredutor para movimentar a ponta de pulverização; E. Analisador de partículas a laser.

O experimento foi conduzido em delineamento inteiramente ao acaso, em esquema fatorial ( $2 \mathrm{x}$ $2 \times 4$ ), sendo dois modelos de pontas hidráulicas (AI3070-015VP e AI3070-02VP), dois leques (30 e $\left.70^{\circ}\right)$ e quatro pressões de trabalho $(200,300,400$ e $500 \mathrm{kPa}$ ). Visando minimizar os erros, para cada modelo de ponta de pulverização, escolheram-se aleatoriamente três pontas em um lote de dez, as quais foram devidamente identificadas ao longo do ensaio. Para cada ponta realizaram-se cinco repetições, perfazendo 15 repetições por tratamento. Os parâmetros técnicos da pulverização analisados foram o diâmetro da gota abaixo do qual está contido $10 \%$ do volume correspondente às gotas da amostra $\left(\mathrm{DV}_{0,1}\right)$, diâmetro da mediana volumétrica $\left(\mathrm{DV}_{0,5}\right)$; diâmetro da gota abaixo do qual está contido $90 \%$ do volume correspondente às gotas da amostra $\left(\mathrm{DV}_{0,9}\right)$; Índice Span; porcentagem do volume de gotas com diâmetro abaixo de $100 \mu \mathrm{m}$ $(\%<100 \mu \mathrm{m})$ e porcentagem do volume de gotas com diâmetro acima de $650 \mu \mathrm{m}(\% \mathrm{~V}>650 \mu \mathrm{m})$. As pulverizações foram realizadas com a ponta a uma distância de $0,2 \mathrm{~m}$ do feixe de luz do analisador de partículas. As condições psicrométricas do ar foram monitoradas durante todo o experimento usando um termohigroanemômetro, modelo TAD -800 , Instrutherm.

\section{RESULTADOS E DISCUSSÕES}

$\mathrm{O}$ experimento foi realizado sob condições de ausência de vento, temperatura entre 24,5 e $28,6^{\circ} \mathrm{C}$ e a umidade relativa do ar entre 55 e $79 \%$.

A vazão produzida pelas pontas hidráulicas aumentou linearmente, na faixa de pressão estudada (Figura 2).

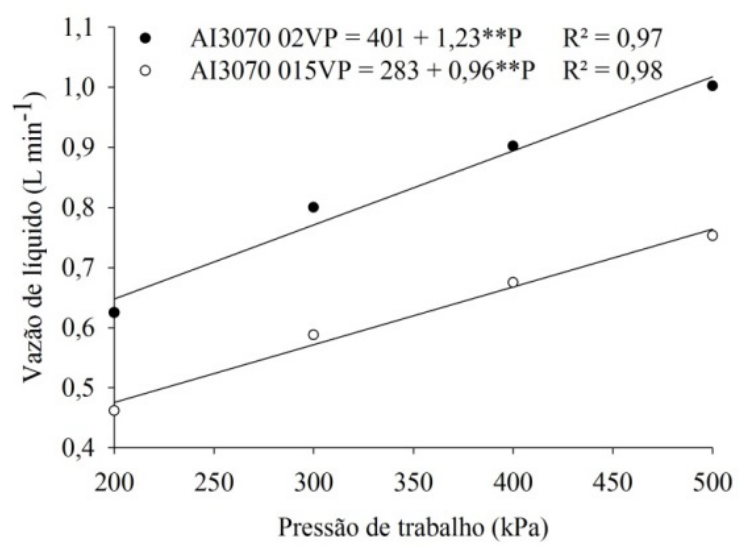

Figura 2. Vazão de líquido proporcionado pelas pontas AI3070-02VP e AI3070-015VP sob diferentes condições operacionais. **Significativo pelo teste $\mathrm{t}$ ao nível de $1 \%$ de probabilidade.

Este comportamento corrobora com os resultados obtidos por Vitória et al. (2014), que utilizaram pontas hidráulicas do tipo cone vazio. Para uma determinada ponta de pulverização hidráulica, a vazão de líquido é diretamente proporcional à raiz quadrada da pressão (TADIĆ et al., 2014). Os resultados demonstram ainda que as pontas testadas estão em conformidades com a norma ISO 10625 (2005). 
Em relação ao espectro de gotas, os valores médios obtidos para as variáveis, $\mathrm{DV}_{0,1}, \mathrm{DV}_{0,5}$ e $\mathrm{DV}_{0,9}$, indicaram que a ponta AI3070-02VP apresentou maior diâmetro das gotas em relação à AI3070-015VP. Estes resultados corroboram com Tadic et al. (2014), Gil et al. (2014) e Nuyttens et al. (2007), que avaliaram outros modelos de pontas hidráulicas e constataram que, para o mesmo modelo de ponta, quanto maior a vazão nominal maior é o tamanho das gotas pulverizadas. $\mathrm{Na}$ análise da interação entre o modelo da ponta versus tipo de leque constatou-se que, para a AI3070$015 \mathrm{VP}$, o leque de $30^{\circ}$ apresentou menor diâmetro das gotas quando comparado ao leque de $70^{\circ}$. Entretanto, ao se empregar a ponta AI3070-02VP o comportamento foi o inverso.

O tamanho de gotas médio para as variáveis analisadas foi maior na ponta AI3070-02VP, de maior vazão, resultado considerado normal quando se estuda o espectro de gotas de pontas com vazão diferente na mesma pressão de trabalho (Quadro 1).

Comparando-se os leques de 30 e $70^{\circ}$, observouse que, para os parâmetros $\mathrm{DV}_{0,1}$ e $\mathrm{DV}_{0,9}$ os diferentes modelos de pontas apresentaram valores semelhantes, com alteração de no máximo $18 \%$ no $\mathrm{DV}_{0,9}$, para a ponta AI3070-02VP. Estes resultados são consequências das diferenças de projeto nos orifícios de saída de calda em ambas as pontas. $\mathrm{O}$ $\mathrm{DV}_{0,1}$ representa o diâmetro de gota tal que $10 \%$ do volume do líquido pulverizado é constituído de gotas menores que esse valor e pode representar aquelas gotas com grande probabilidade de serem aplicadas fora do alvo, em função da temperatura, umidade relativa e velocidade do vento, ao passo que, o $\mathrm{DV}_{0,9}$ demonstra o tamanho de gotas no qual $90 \%$ do volume do líquido pulverizado é constituído de gotas menores que esse valor. Os parâmetros $\mathrm{DV}_{0,1}$ e $\mathrm{DV}_{0,9}$ são parâmetros pouco discutidos na literatura. São utilizados para determinar a dispersão do tamanho das gotas. A norma ASABE
S.572.1 (ASABE, 2009) e alguns fabricantes utilizam os valores destes dois parâmetros para auxiliar na classificação do espectro de gotas, variando entre muito fina e extremamente grossas.

Nas presentes condições, o $\mathrm{DV}_{0,5}$, médio de 365 $\mu \mathrm{m}$ é considerado grande e pode ser um limitante em caso de aplicações que requerem alta cobertura do alvo, principalmente quando se trata de produtos de contato.

Quanto ao parâmetro $\mathrm{DV}_{0,9}$, este apresentou valor maior que $500 \mu \mathrm{m}$ para ambas as pontas. A maior distância entre o tamanho das gotas que representam o $\mathrm{DV}_{0,1}$ e aquelas que representam o $\mathrm{DV}_{0,9}$ implicará em maior heterogeneidade do espectro de gotas produzido pelas pontas.

A amplitude relativa ou Span é um ótimo índice de avaliação do espectro de gotas, pois permite uma análise conjunta da maioria das gotas produzidas pela ponta. Este é ideal quando seu valor é zero, porém este valor não é observado nas pontas comerciais devido às mesmas produzirem gotas de tamanhos variados.

Os valores obtidos para a amplitude relativa, os quais indicam a uniformidade do espectro de gotas, demonstram que a ponta de maior vazão no ângulo de $30^{\circ}$ produziu a população de gotas mais heterogêneas. Nas condições avaliadas, este parâmetro variou entre 1,5 e 1,6, valores próximos aos obtidos por Cunha et al., (2010) utilizando pontas TT 11002 e TTI 11002, esta última também com indução de ar.

A percentagem de gotas com tamanho menor que $100 \mu \mathrm{m}$ apresentou um valor baixo, o que é desejável devido ao potencial de perdas apresentados por estas gotas. Já a percentagem de gotas com tamanho maior que $650 \mu \mathrm{m}$ foi maior no jorro de $30^{\circ}$ para a ponta de maior vazão, comportamento natural das pontas hidráulicas em função de sua vazão nominal (Quadro 2).

Quadro 1. Média do espectro de gotas proporcionado pelas pontas AI3070-015VP e AI3070-02VP

\begin{tabular}{|c|c|c|c|c|c|c|c|c|c|}
\hline \multirow{3}{*}{ Ponta } & \multirow{2}{*}{\multicolumn{2}{|c|}{$\frac{\mathrm{DV}_{0,1}(\mu \mathrm{m})}{\text { Leque }\left({ }^{\circ}\right)}$}} & \multirow{3}{*}{$\overline{\mathrm{x}}$} & \multirow{2}{*}{\multicolumn{2}{|c|}{$\frac{\mathrm{DV}_{0,5}(\mu \mathrm{m})}{\text { Leque }\left(^{\circ}\right)}$}} & \multicolumn{4}{|c|}{$\mathrm{DV}_{0,9}(\mu \mathrm{m})$} \\
\hline & & & & & & $\bar{v}$ & Lec & & $\bar{\nabla}$ \\
\hline & 30 & 70 & & 30 & 70 & & 30 & 70 & \\
\hline AI3070-015VP & $127 \mathrm{aB}$ & $145 \mathrm{aA}$ & $136 \mathrm{~b}$ & $356 \mathrm{bB}$ & $378 \mathrm{aA}$ & $365 b$ & $674 \mathrm{bB}$ & $726 \mathrm{aA}$ & $700 \mathrm{~b}$ \\
\hline AI3070-02VP & $153 \mathrm{aA}$ & $140 \mathrm{aB}$ & $146 \mathrm{a}$ & $411 \mathrm{aA}$ & $357 \mathrm{bB}$ & $384 a$ & $834 \mathrm{aA}$ & $690 \mathrm{bB}$ & $762 \mathrm{a}$ \\
\hline
\end{tabular}

Médias seguidas por letras iguais, maiúsculas na linha e minúsculas na coluna, não diferem entre si pelo teste Tukey à 5\% de probabilidade. $\overline{\mathrm{X}}=$ média dos valores. 
Quadro 2. Média do índice Span e porcentagem de classes de gotas proporcionadas pelas pontas AI3070015VP e AI3070-02VP

\begin{tabular}{|c|c|c|c|c|c|c|c|c|c|}
\hline \multirow{3}{*}{ Ponta } & \multicolumn{3}{|c|}{ Span } & \multicolumn{3}{|c|}{$\% \mathrm{~V}<100$} & \multicolumn{3}{|c|}{$\% \mathrm{~V}>650$} \\
\hline & \multicolumn{2}{|c|}{ Leque $\left({ }^{\circ}\right)$} & \multirow{2}{*}{$\overline{\mathrm{x}}$} & \multicolumn{2}{|c|}{ Leque $\left(^{\circ}\right)$} & \multirow{2}{*}{$\overline{\mathrm{x}}$} & \multicolumn{2}{|c|}{ Leque $\left({ }^{\circ}\right)$} & \multirow{2}{*}{$\overline{\mathrm{x}}$} \\
\hline & 30 & 70 & & 30 & 70 & & 30 & 70 & \\
\hline AI3070-015VP & $1,5 \mathrm{bA}$ & $1,5 \mathrm{aA}$ & $1,5 b$ & $6,9 \mathrm{aA}$ & $6,4 \mathrm{aB}$ & $6,7 \mathrm{a}$ & $16,3 \mathrm{bB}$ & $20,3 \mathrm{aA}$ & $18,3 b$ \\
\hline AI3070-02VP & $1,6 \mathrm{aA}$ & $1,5 \mathrm{aB}$ & $1,6 \mathrm{a}$ & $5,1 \mathrm{bB}$ & $6,1 \mathrm{aA}$ & $5,6 \mathrm{~b}$ & $24,9 \mathrm{aA}$ & $17,6 \mathrm{bB}$ & $21,2 \mathrm{a}$ \\
\hline
\end{tabular}

Médias seguidas por letras iguais, maiúsculas na linha e minúsculas na coluna, não diferem entre si pelo teste Tukey à $5 \%$ de probabilidade. $\overline{\mathrm{X}}_{=}$média dos valores.

A porcentagem de gotas com diâmetro inferior a $100 \mu \mathrm{m}$ determina o potencial risco de deriva em uma pulverização de campo (ARVIDSSON et al., 2011). No presente trabalho, as pontas com indução de ar apresentaram em média uma pequena quantidade de gotas nesta classe. Cunha et al. (2003) relataram que, para realizar uma pulverização segura, é recomendado no máximo $15 \%$ de gotas com diâmetro abaixo de $100 \mu \mathrm{m}$, valor muito acima do máximo obtido neste trabalho que foi de $6,9 \%$.

As pontas de leque duplo defasado em todos os parâmetros analisados proporcionaram diâmetro de gotas entre médias e grossas, característico de ponta com indução de ar. Este modelo de ponta, geralmente, é recomendado para aplicação de produtos sistêmicos ou que requerem pouca cobertura do alvo. Diante da conformação dos jorros produzidos, essas pontas podem minimizar o efeito guarda chuva e aumentar a penetração das gotas no dossel da planta. A aplicação de agrotóxicos tem buscado aliar o diâmetro das gotas e a cobertura do alvo. Diversas pesquisas demonstram que gotas com maior diâmetro podem proporcionar a mesma eficácia de controle ou até mesmo superior, comparado às gotas finas (JULIATTI et al., 2010; GULART et al., 2013).

A introdução da tecnologia de indução de ar em pontas hidráulicas teve como um de seus objetivos elevar o tamanho das gotas, fato alcançado com sucesso. Durante os ensaios, as pontas analisadas apresentaram percentagem de gotas com diâmetro maior que $650 \mu \mathrm{m}$ que foram considerados elevados para a aplicação de agrotóxicos, mesmo que sejam para a aplicação de produtos sistêmicos, pois uma grande parte do produto contido nestas gotas é perdido por escorrimento, corroborando com Silva et al. (2014).

O efeito da pressão de trabalho nas variáveis do espectro de gotas, independente da vazão nominal da ponta e do ângulo de jorro indicou que, com o incremento da pressão, houve uma redução no $\mathrm{DV}_{0,1}, \mathrm{DV}_{0,5}, \mathrm{DV}_{0.9}$ e na porcentagem do volume de gotas com diâmetro maior que $650 \mu \mathrm{m}$. O comportamento inverso foi observado para o índice Span e a porcentagem de gotas com diâmetro abaixo de $100 \mu \mathrm{m}$ (Figura 3).

Os resultados obtidos representam o comportamento característico das pontas hidráulicas em condições de variação da pressão de trabalho. Os parâmetros do espectro de gotas $\mathrm{DV}_{0,1}, \mathrm{DV}_{0,5}, \mathrm{DV}_{0,9}$, que são mensurados diretamente, apresentam valores menores à medida que a pressão é aumentada dentro da faixa de pressão recomendada para cada ponta hidráulica. Em diversos trabalhos como o desenvolvido por Czaczyk et al. (2012) e Bueno et al. (2013), as gotas apresentam o mesmo comportamento em função da pressão.

O percentual de gotas com tamanho acima de 650 $\mu \mathrm{m}$ também reduziu com o incremento da pressão de trabalho. Na aplicação de agrotóxicos deve-se selecionar o tamanho de gotas que proporcione uma cobertura desejada. Ainda recomenda-se observar a porcentagem de gotas acima de $650 \mu \mathrm{m}$ minimizando as perdas por escorrimento da calda para o solo, bem como observar a percentagem de gotas com tamanho abaixo de $100 \mu \mathrm{m}$, evitando-se assim perdas por deriva e evaporação, logo menor contaminação ambiental e desperdícios financeiros para o produtor. 


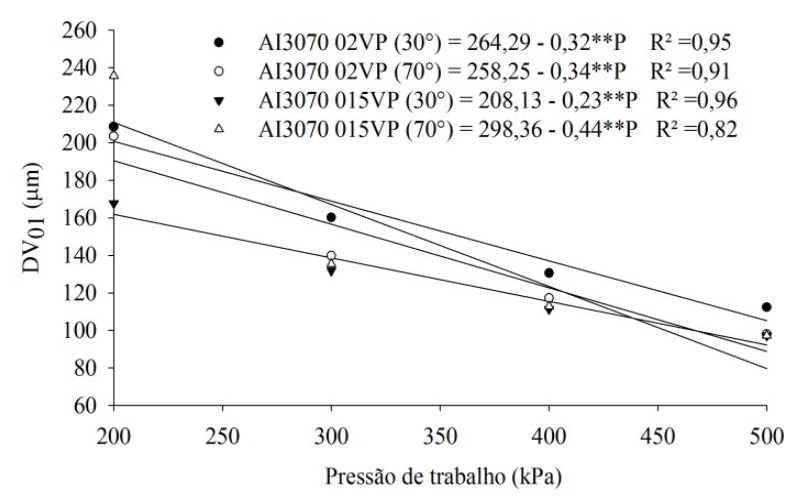

(A)

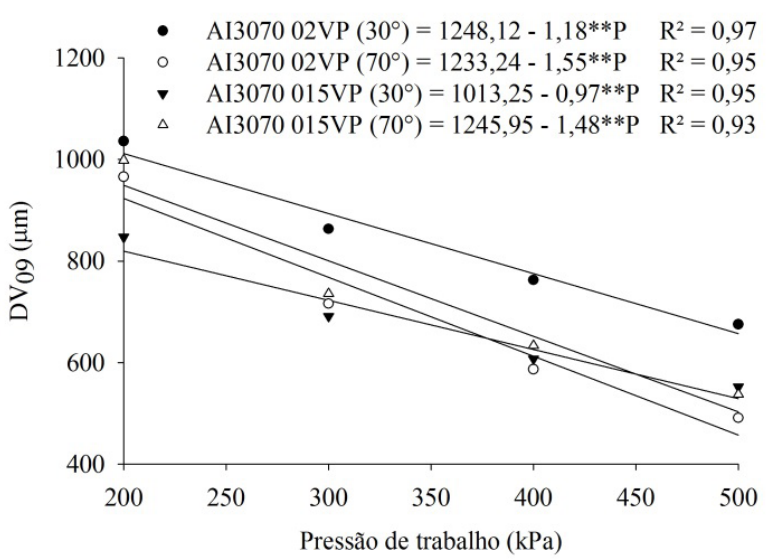

(C)

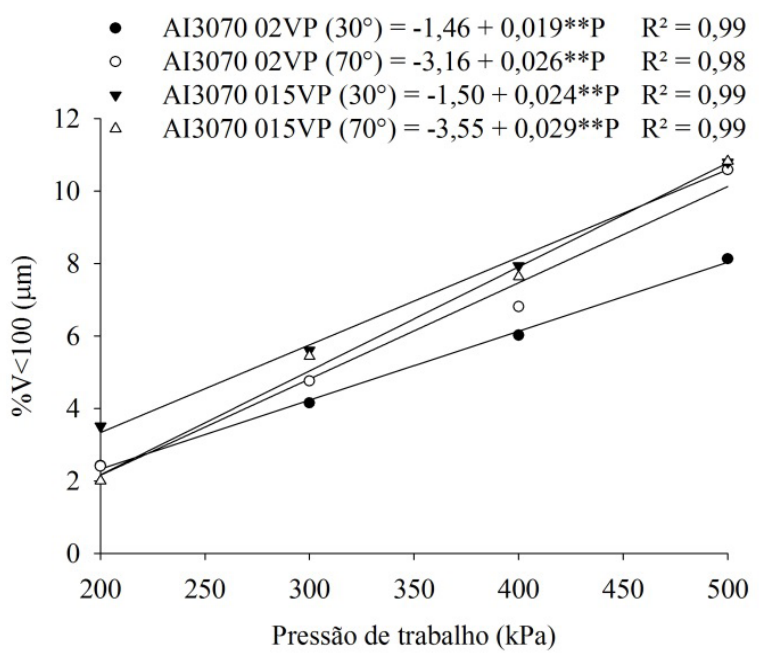

(E)

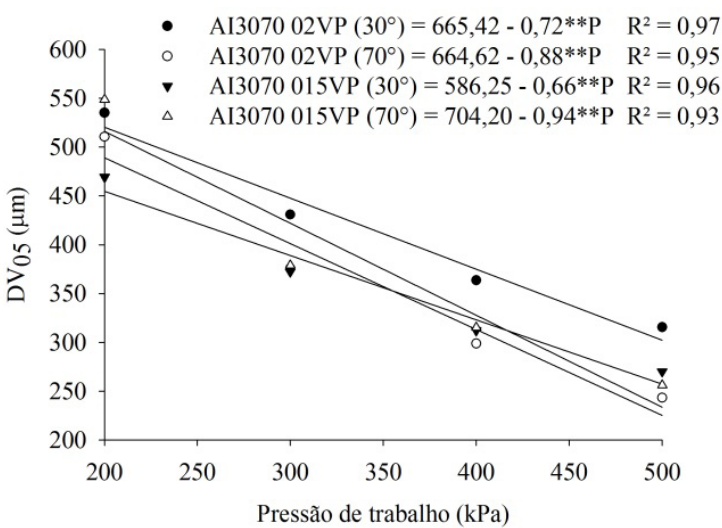

(B)

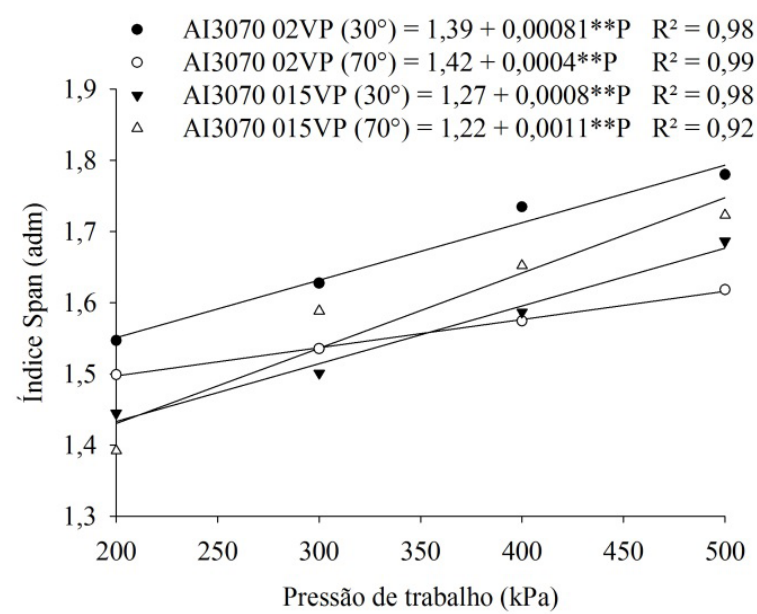

(D)

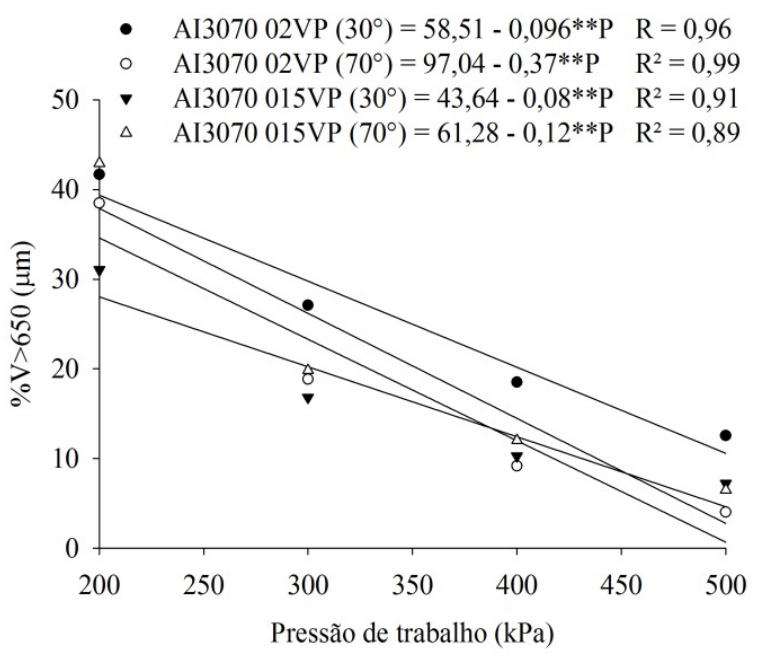

(F)

Figura 3. Efeito da pressão de trabalho nas variáveis (A) $\mathrm{DV}_{0,1}$; (B) $\mathrm{DV}_{0,5}$; (C) $\mathrm{DV}_{0,9}$; (D) Índice Span; (E) $\% \mathrm{~V}<100 \mu \mathrm{m}$ e (F) $\% \mathrm{~V}>650 \mu \mathrm{m}$. **Significativo pelo teste $\mathrm{t}$ ao nível de $1 \%$ de probabilidade.

A amplitude relativa aumentou com o acréscimo da pressão de trabalho devido, principalmente, ao aumento da distância entre o $\mathrm{DV}_{0,1}$ e o $\mathrm{DV}_{0,9}$. $\mathrm{O}$ efeito da elevação da pressão nas gotas que compõem o $\mathrm{DV}_{0,9}$ é maior, facilmente observada na inclinação das retas, em que as gotas grandes são fracionadas com maior facilidade que as pequenas e a consequência disso é um aumento

\section{REVENG}

211-218p. 
no Span. Este resultado indica que a população de gotas é composta por uma diversidade muito grande de tamanhos de gota, ou seja, apresenta maior amplitude. Esta situação não significa que a aplicação será ruim ou ineficiente, uma vez que outros aspectos interagem com a gota após ela ser pulverizada, até alcançar o alvo.

Conhecer detalhadamente o comportamento do espectro de gotas proporcionado pelas pontas hidráulicas é fundamental, haja vista que o tamanho das gotas influencia na eficiência da pulverização e na eficácia de controle dos agentes nocivos às culturas, bem como nos possíveis impactos ambientais e perdas de produto. A pressão de trabalho ideal para as pontas depende do tratamento químico e o alvo a ser atingido. Em uma aplicação de agrotóxicos, muitos agricultores ajustam o volume de calda pela pressão de trabalho, o que resulta na alteração do espectro de gotas. Sempre que possível, a alteração do volume de pulverização por meio da pressão deve ser realizada conscientemente e, em casos de grandes alterações, é mais recomendado a alteração do tipo de ponta.

Os diferentes leques testados para uma determinada vazão nominal apresentaram comportamentos semelhantes e pouca variação nos parâmetros da pulverização. De acordo com Baesso et al. (2014), gotas menores possuem maior capacidade de penetração no dossel da cultura, neste sentido, esperava-se que o leque de menor angulação apresentasse gotas de menores diâmetros, uma vez que este jorro tem a finalidade de produzir gotas para penetração no dossel da planta. Da mesma forma, esperava-se que o jorro de $70^{\circ}$, inclinado para trás do sentido de deslocamento da máquina, apresentasse gotas relativamente maiores comparados ao leque de $30^{\circ}$, pois este jorro tem por objetivo produzir gotas para maximizar a cobertura na parte superior da planta, entretanto, tais fatos não foram evidenciados.

\section{CONCLUSÕES}

- $\mathrm{Na}$ ponta AI3070-015VP o jato de $70^{\circ}$ apresentou maior diâmetro da mediana volumétrica em relação ao jato de $30^{\circ}$, comportamento inverso ao observado para a ponta AI3070- 02VP.

- As pontas com indução de ar apresentaram baixo percentual de gotas com tamanho menor que $100 \mu \mathrm{m}$, indicando baixo risco de deriva nas aplicações.

- Elevando-se a pressão de trabalho, reduz os valores dos parâmetros $\mathrm{DV}_{0,1}, \mathrm{DV}_{0,5}, \mathrm{DV}_{0.9} \mathrm{e}$ porcentagem do volume de gotas com diâmetro maior que $650 \mu \mathrm{m}$ e aumenta a porcentagem do volume de gotas com diâmetro menor que $100 \mu \mathrm{m}$.

- O potencial de perdas por evaporação e volatilização é baixo, pois o percentual de gotas com tamanho menor que $100 \mu \mathrm{m}$ não ultrapassou $12 \%$ na pressão de $500 \mathrm{kPa}$.

- O potencial de perdas por escorrimento é elevado, pois o percentual de gotas com tamanho superior a $650 \mu \mathrm{m}$ pode alcançar $40 \%$ na pressão de $200 \mathrm{kPa}$.

\section{REFERÊNCIAS BIBLIOGRÁFICAS}

AMERICAN SOCIETY OF AGRICULTURAL AND BIOLOGICAL ENGINEERS. ASABE S.572.1: Spray Nozzle Classification by Droplet Spectra. St. Joseph, USA, 2009. 4p.

ARVIDSSON, T.; BERGSTRÖM, L.; KREUGER, J. Spray drift as influenced by meteorological and technical factors. Pest Management Science, West Sussex, v.67, p.586-598, 2011.

BAESSO, M.M.; TEIXEIRA, M.M.; RUAS, R.A.A.; BAESSO, R.C.E. Tecnologias de aplicação de agrotóxicos. Revista Ceres, Viçosa, v.61, p.780-785, 2014.

BUENO, M.R.; CUNHA, J.P.A.R.; ROMAN, R.A.A. Tamanho de gotas de pontas de pulverização em diferentes condições operacionais por meio da técnica de difração do raio laser. Engenharia Agrícola, Jaboticabal, v.34, n.5, p.976-985, 2013.

CUNHA, J.P.A.R.; BUENO, M.R.; FERREIRA, M.C. Espectro de gotas de pontas de pulverização com adjuvantes de uso agrícola. Planta Daninha, Viçosa, v.28, n.spe., p.1153-1158, 2010. 
CUNHA, J.P.A.R.; RUAS, R.A.A.; TEIXEIRA, M.M. Distribuição volumétrica de pontas de pulverização de jato cônico vazio com indução de ar analisada em mesa de prova e simulação computadorizada. Revista Ceres, v.54, n.311, p.40-46, 2007.

CUNHA, J.P.A.R.; TEIXEIRA, M.M.; COURY, J.R.; FERREIRA, L.R. Avaliação de estratégias para redução da deriva de agrotóxicos em pulverizações hidráulicas. Planta Daninha, Viçosa, v.21, n.2, p.325-332, 2003.

CZACZYK, Z.; KRUGER, G.; HEWITT, A. Droplet size classification of air induction flat fan nozzles. Journal of Plant Protection Research, Poznan, v.52, n.4, p.415-420, 2012.

GIL, E.; BALSARI, P.; GALLART, M.; LLORENS, J.; MARUCCO, P.; ANDERSEN, P.G.; FÀBREGAS, X.; LLOP, J. Determination of drift potential of different flat fan nozzles on a boom sprayer using a test bench. Crop Protection, Philadelphia, v.56, p.58-68, 2014.

GULART, C.A.; DEBORTOLI, M.; MADALOSSO, M.; BALARDIN, R.; SANTOS, P.S.; CORTE, G.D.; LENZ, G.; MARQUES, L.N. Espectro de gotas de pulverização e controle de doenças em duas cultivares de trigo. Ciência Rural, Santa Maria, v.43, n.10, p.1747-1753, 2013.

JULIATTI, F.C.; NASCIMENTO, C.; REZENDE, A.A. Avaliação de diferentes pontas e volumes de pulverização na aplicação de fungicida na cultura do milho. Summa Phytopathologica, Botucatu, v.36, n.3, p.216-221, 2010.

LENZ, G.; BALARDIN, R.S.; MINUZZI, S.G.; MADALOSSO, M.; DEBORTOLI, M. GULART, C.; RAMOS, J.P. Espectro de gotas e idade de trifólios e sua interação com a área abaixo da curva de progresso da ferrugem da soja. Ciência Rural, Santa Maria, v.42, n.9, p.1528-1534, 2012.

NUYTTENS, D.; BAETENS, K.; SCHAMPHELEIRE, M.; SONCK, B. Effect of nozzle type, size and pressure on spray droplet characteristics. Biosystems Engineering, Philadelphia, v.97, p.333-345, 2007.

SILVA, J.E.R.; CUNHA, J.P.A.R.; NOMELINI, Q.S.S. Deposição de calda em folhas de cafeeiro e perdas para o solo com diferentes taxas de aplicação e pontas de pulverização. Revista de Engenharia Agrícola e Ambiental, Campina Grande, v.18, n.12, p.1302-1306, 2014.

TADIC, V.; MARKOVIC, M.; PLASCAK, I.; STOSIC, M.; LUKINAC-CACIC, J.; VUJCIC, B. Impacto of technical spraying factors on leaf area coverage in an apple orchard. Tehnicki Vjesnik, v.21, n.5, p.1117-1124, 2014.

VALLET, A.; TINET, C. Characteristics of droplets from single and twin jet air induction nozzles: A preliminary investigation. Crop Protection, Philadelphia, v.48, p.63-68, 2013.

VITÓRIA, E.L.; LEITE, J.U.Q. Espectro de gotas de pontas de pulverização de jato cônico vazio. Enciclopédia Biosfera, Goiânia, v.10, n.18, p.1551-1559, 2014. 